\title{
Born to be free: the influence of raising the awareness of the nursing staff to the reduction of the use of physical restraints on restraint orders, hours of restraint and the numbers of patients restrained - a retrospective study
} Sagit Dahan*, Galit Levi, Pnina Behrbalk, Yuval Melamed and Avi Bleich

Address: Lev-Hasharon Mental Health Center, Netanya, Israel/Sackler Faculty of Medicine, Tel-Aviv University, Israel

* Corresponding author

from WPA Thematic Conference. Coercive Treatment in Psychiatry: A Comprehensive Review

Dresden, Germany. 6-8 June 2007

Published: 19 December 2007

BMC Psychiatry 2007, 7(Suppl I):P6 doi:10.1 186/147I-244X-7-SI-P6

This abstract is available from: http://www.biomedcentral.com/I47I-244X/7/SI/P6

(C) 2007 Dahan et al; licensee BioMed Central Ltd.

\section{Background}

Restraint of psychiatric patients is an ethical issue, emphasized by awareness of the rights of mentally ill individuals. Restraint significantly influences the emotional welfare of the patient, is traumatic, deprives the individual of freedom and has aggressive connotations. Aims: To examine the influence of raising the awareness of the staff to reduce use of physical restraints. Hypothesis: Raising the awareness of the staff will lead to a reduction in the number of restraining orders, the duration of restraints and the number of patients restrained.

\section{Methods}

We collected data regarding the number of restraints. Intervention included reduction of restraint policy and trimonthly meetings to evaluate use of restraints and alternative methods which avoid physical restraints. Data were collected anonymously from four departments where physical restraints are used. Data collection took place twice: following the year of awareness intervention (July 2005 - June 2006), and was compared to the previous year (July 2004 - June 2005), when there was no intervention.

\section{Results}

Significant correlations were found between the groups before and after the intervention. The mean number of restraint orders prior to the intervention was $30.8(\mathrm{SD}=$ 24.4) and after intervention $22.4(\mathrm{SD}=17.6) ; \mathrm{p}=.03, \mathrm{t}=$
2.3. There was no significant difference between the departments in the reduction of restraint orders. In the year prior to intervention there was no correlation between occupancy and the number of restraints, and one year post intervention there was a significant correlation between occupancy and the number of restraint orders ( $p$ $=.001)$ and occupancy and the number of patients restrained $(\mathrm{p}=.001)$.

\section{Conclusion}

Intervention to raise the awareness of the staff to reduce restraints was effective and lead to a reduction in the number of restraints. This is important for creating a professional, supportive, and safe therapeutic environment for the patients. 